\title{
Moult cycle-related changes in feeding rates of larval krill Meganyctiphanes norvegica and Thysanoessa spp.
}

\author{
Katrin Schmidt ${ }^{1,2, *}$, Geraint A. Tarling ${ }^{2}$, Nicola Plathner ${ }^{1}$, Angus Atkinson ${ }^{2}$ \\ ${ }^{1}$ Institute for Baltic Sea Research Warnemünde, Seestrasse 15, 18119 Rostock, Germany \\ ${ }^{2}$ British Antarctic Survey, Natural Environment Research Council, High Cross, Madingley Road, Cambridge CB3 0ET, UK
}

\begin{abstract}
Knowledge of crustacean moulting is derived mainly from benthic decapods, which often show profound changes in physiology and behaviour through the moult cycle. In contrast, euphausiids are suggested to be little impaired by moulting, enabling a swarming pelagic life. The aim of this study was to quantify moult cycle-related changes in the feeding activity of 2 euphausiids, Meganyctiphanes norvegica and Thysanoessa spp. Late furcilia larvae and early postlarvae were kept individually over 6 to $7 \mathrm{wk}$ and fed with either a high or low concentration of Artemia salina nauplii or particulate fish food. The intermoult period, $\sim 9 \mathrm{~d}$ for $M$. norvegica and $\sim 8 \mathrm{~d}$ for Thysanoessa spp., increased with body weight, but did not differ with food source. Moulting was partially synchronised, with up to $50 \%$ of the individuals moulting within $48 \mathrm{~h}$ of each other. Daily feeding rates on A. salina decreased on the day before moulting, but increased during the next few days with highest values on Days 1 to 3 after moulting. The deviation from the mean feeding rate over the whole moult was more pronounced at the higher food concentration, reaching up to $40 \%$. Likewise, the defecation volume was reduced on the moulting day and the following day to $~ 50 \%$ of the mean, but increased to $180 \%$ of the mean on Day 3 after moulting. Thus, the moult cycle induces significant changes in feeding rates of larval euphausiids with a similar succession of events and intensity as observed in decapods. Feeding rates, extrapolated from spot measurements on a few individuals, are unlikely to represent average values over the whole moult cycle, especially when populations moult synchronously. We propose a protocol to increase the precision of field estimates on feeding rates.
\end{abstract}

KEY WORDS: Moulting - Feeding - Defecation - Krill $\cdot$ Larvae $\cdot$ Meganyctiphanes norvegica Thysanoessa spp.

Resale or republication not permitted without written consent of the publisher

\section{INTRODUCTION}

Being encased in a rigid exoskeleton, crustaceans have to shed their cuticle periodically to allow for growth, development and regeneration. The actual act of shedding the old exoskeleton (ecdysis) is the most obvious manifestation of the moult cycle, but the vast majority of the events related to this cycle occur internally (Skinner 1985, Roer \& Dillaman 1993). Proecdysis involves the separation of the underlying epidermal cells from the old exoskeleton, resorption of organic and inorganic components, and generation of the new cuticle. At ecdysis, the old exoskeleton breaks and the new, flexible exoskeleton expands by taking up water. Postecdysis is characterised by mineralisation and further deposition of cuticle. The main tissue growth and accumulation of organic reserves usually occurs between postecdysis and the onset of the next proecdysis.

The integumentary reorganisation during the moult cycle is necessarily linked with biochemical, physiological and behavioural changes. Those modifications have mainly been studied in benthic or semibenthic decapods. These species show increased oxygen consumption and ammonium excretion rates before, during and shortly after ecdysis (e.g. Penkoff \& Thurberg 
1982, Carvalho \& Phan 1998, Taylor et al. 2002), suggesting high metabolic requirements during this period (Chang 1995). Shedding of the entire chitinous lining of the fore and hindgut (Passano 1960) is reflected in inhibited feeding (Chittleborough 1975, Strong \& Daborn 1980, Lipcius \& Herrnkind 1982). In addition, food preferences might alter around ecdysis because of different nutritional requirements during this stage (Bernardez et al. 2000, de Lestang et al. 2000). The new, soft exoskeleton often limits mobility and the use of defensive appendages in decapods, which makes them especially vulnerable to predation (Chang 1995). Therefore, moulting decapods often hide or avoid contact with conspecifics (Lipcius \& Herrnkind 1982, Chang 1995).

In contrast to benthic decapods, there are few studies on moult cycle-related physiological alterations in pelagic species. Among euphausiids, the evidence is conflicting. Ecdysis happens extremely quickly in Antarctic krill Euphausia superba, and Buchholz $(1989,1991)$ suggested that their motility and feeding is little impaired by moulting. This has been interpreted as a prerequisite for a pelagic life and moving in swarms (Buchholz 1991). However, detailed measurements on another euphausiid, Meganyctiphanes norvegica, show that newly moulted krill have lower swimming capacity than non-moulting conspecifics (Thomasson et al. 2003). The fact that moulting $M$. norvegica do not undergo diel vertical migration but stay at depth further supports the argument that swimming performance and/or behaviour of krill is affected by ecdysis (Tarling et al. 1999). Other studies indicate reduced feeding activity (Lasker 1966, Paranjape 1967, Morris 1985) and increased oxygen consumption in moulting euphausiids (Paranjape 1967, Ikeda \& Mitchell 1982). However, none of these studies has followed changes in physiological rates over the whole moult cycle and so do not allow the effect of moulting to be quantified.

A quantification of physiological alterations during the moult cycle is important, because firstly, it will help to distinguish between physiological and behavioural changes. For instance, the empty stomachs typical of moulting krill (Morris 1985) might be due to an extended physiological inability to feed or a consequence of a changed migration behaviour avoiding predation and cannibalism (Morris 1985, Tarling et al. 1999). Secondly, the environmental controls on feeding or respiration rates can only be identified accurately when internal cycles are first taken into account. In the isopod Idotea baltica, for instance, the moult stage causes more than $30 \%$ of the total variation in ingestion rates (Strong \& Daborn 1980). Likewise, ignoring moult cycle-related changes in physiological rates might lead to errors in bioenergetic models. Metabolic rates integrated over a whole moult cycle were $\sim 30 \%$ higher than traditional spot measurements on nonmoulting shrimp (Carvalho \& Phan 1998). Thus, 'average' physiological rates extrapolated from spot measurements of a few individuals might be biased, especially when moulting is synchronised as occasionally observed for euphausiids (Morris 1985, Tarling \& Cuzin-Roudy 2003).

The aim of this study was to examine whether feeding rates of euphausiids are affected by the moult cycle in a manner similar to that described for benthic decapods. Northern krill, Meganyctiphanes norvegica and Thysanoessa spp. (T. raschii and T. inermis), were chosen for study. These species are central components in food webs of the northern Atlantic and fringing shelves, utilising diverse food sources and comprising important prey for fish, birds and marine mammals (Mauchline 1980, Falk-Petersen \& Hopkins 1981, Dalpadado et al. 2000). However, experimental studies on their early developmental stages are rare (Le Roux 1974). Here we incubated late furcilia and early postlarvae of M. norvegica and Thysanoessa spp. individually, with various foods for a period of 6 to $7 \mathrm{wk}$ to examine their moulting activity and related changes in feeding and defecation rates.

\section{MATERIALS AND METHODS}

Krill sampling. Late furcilia larvae and early postlarvae of Meganyctiphanes norvegica and Thysanoessa spp. (T. raschii and T. inermis) were collected in the deep basin of the Gullmarsfjord, west coast of Sweden $\left(58^{\circ} 19.00^{\prime} \mathrm{N}, 11^{\circ} 33.00^{\prime} \mathrm{E}\right)$. Samples were taken on the morning of 5 September 2000 using an Isaac-Kidd midwater trawl (mesh size $1500 \mu \mathrm{m}$ ). About 200 specimens pooled from several net catches were sorted into $30 \mathrm{l}$ plastic tanks of seawater and transported to the laboratory. A subsample of the freshly caught krill was immediately frozen at $-80^{\circ} \mathrm{C}$ for later estimation of lengthweight relationships, carbon and nitrogen content, and trophic position via stable nitrogen isotopes according to Peterson \& Fry (1987).

Experiments. Experiments were carried out in dim blue light in a room with constant temperature $\left(8^{\circ} \mathrm{C}\right)$. Krill were transferred individually to separate $800 \mathrm{ml}$ Kautex bottles filled with $1 \mu \mathrm{m}$ filtered fjord seawater (35 m depth) (33 PSU, $\mathrm{O}_{2}>80 \%$ saturation). The initial wet weight of each individual was measured within $1 \mathrm{~d}$ of capture using a Mettler microbalance. Thereafter, were divided into 3 groups, each group being fed with either 100 freshly hatched brine shrimp Artemia salina (L.) nauplii, $300 \mathrm{~A}$. salina nauplii or about $5 \mathrm{mg}$ of the commercial fish food 'Artemac' (Aquafauna ${ }^{\mathrm{R}}$ ). Nauplii had an atomic $\mathrm{C}: \mathrm{N}$ ratio of $\sim 6.1$, and about $1.1 \mu \mathrm{g} \mathrm{C}$ 
ind. $^{-1}$ and $0.2 \mu \mathrm{g} \mathrm{N}$ ind. ${ }^{-1}$. The fish food had a particle size of 100 to $200 \mu \mathrm{m}$, a C:N ratio of $\sim 6.0$, and $0.42 \mathrm{mg} \mathrm{C}$ and $0.08 \mathrm{mg} \mathrm{N} \mathrm{mg}^{-1}$ dry weight. Thus, 100 nauplii of A. salina comprised a total food concentration of $\sim 0.1 \mathrm{mg} \mathrm{C}$, while $5 \mathrm{mg}$ of fish food was equivalent to $2.1 \mathrm{mg} \mathrm{C}$.

Moulting and feeding rates on Artemia salina nauplii were monitored beginning on 7 September 2000. Each individual was transferred daily to a fresh bottle of filtered seawater and a new supply of food. The previous incubation water was sieved through $55 \mu \mathrm{m}$ mesh to collect moults, faecal pellets and remaining nauplii. The daily feeding rate, $F$, was calculated for each individual as: $F=n_{\mathrm{i}}-n_{\mathrm{f}}$, where $n_{\mathrm{i}}$ is the initial number of nauplii and $n_{\mathrm{f}}$ is the number of nauplii after $24 \mathrm{~h}$. Krill produced only a few very delicate faecal pellets when fed with A. salina, but numerous hard faecal pellets of various sizes when feeding on fish food. Over a period of about $2 \mathrm{wk}$, faecal pellets of 7 large specimens of the group fed with fish food were counted and collected on GF/F filters. The length $(L)$ and diameter $(d)$ of the pellets was measured under a calibrated stereomicroscope. The defecation volume $(V)$ was calculated as: $V=\left(L \times \pi \times d^{2}\right) / 4$.

Experiments were started with 30 individuals feeding on 100 nauplii of Artemia salina, 30 feeding on 300 nauplii of $A$. salina and 50 feeding on particulate fish food. However, the mortality of krill was high within the first $\sim 8 \mathrm{~d}$ after capture, as has been reported from other studies (e.g. Antezana et al. 1982, Clarke \& Morris 1983). Animals which survived that period usually remained alive until the end of the experiment, 6 to $7 \mathrm{wk}$ later. The study includes only those individuals that underwent at least 3 moult cycles and were in good condition over the experimental period. The final wet weight was measured before animals were frozen at $-80^{\circ} \mathrm{C}$.

Biochemical analysis. Krill were thawed and species were identified according to Einarsson (1945). The body length was measured from the anterior lateral edge of the carapace to the posterior edge of the sixth abdominal segment (Standard length 3, Kirkwood 1982). Further treatment was according to body size: specimens $<1.5 \mathrm{mg}$ dry weight were dried at $60^{\circ} \mathrm{C}$ for 24 to $48 \mathrm{~h}$ and analysed whole, while larger specimens were freeze-dried, ground in an agate mortar and subsamples were analysed. Dry weight was determined using a Sartorius ultra-microbalance. The total $\mathrm{C}$ and $\mathrm{N}$ content was determined using a CHN analyser (Thermofinnigan CE 1108) calibrated with an acetanilide standard. Stable isotope ratios of freshly caught krill were analysed according to Schmidt et al. (2003).

Statistical analyses. The effect of body weight and feeding rate on intermoult period was analysed using multiple regression. Moulting synchrony was tested by assessing the goodness of fit of the observed to the expected cumulative moulting frequency distribution (Kolmogorov-Smirnov 1-sample test). A 2-way analysis of variance (ANOVA) was used to examine differences in feeding or defecation rates in relation to individual and day of the moult cycle. The null hypothesis that there was no difference between mean feeding or defecation rates over the whole moult cycle and rates on particular days of the cycle was tested with a 1 -sample $t$-test. Differences were considered significant when $\mathrm{p} \leq 0.05$. Mean values $\pm 1 \mathrm{SD}$ are given throughout the text and tables.

Maximum likelihood model. We used a model to investigate the implications of our findings for a hypothetical field-sampling scenario. In field situations, a population is often sampled only once to determine its in situ feeding rate. However, if feeding rates are biased by the moult stage and there is moulting synchrony in a population, repeated sampling and averaging may improve the approximation. This assumption was tested using a maximum likelihood model with bootstrapping (Hilborn \& Mangel 1997).

The mean feeding rate over the total duration of the experiment was determined for each individual in every group. The feeding rate on any particular day was divided by this mean rate to give a percentage value for that day. The daily feeding rates were then classified according to stage of the moult cycle. Day 1 was the day of moult and the following days were labelled Day 2, 3, $4 \ldots$ up to the last day before moult, which was usually Day 9. Normally, Krill went through 5 moult cycles during the experiments. The value used by the model was the mean of the 5 values for each respective moult day.

The model randomly sampled the experimental population to create a new sample of 30 animals. The day of sampling for this population was then chosen randomly (this would be akin to a field situation, where the researcher would not know which moult stage dominated the population when sampled). The average feeding rate of the population on this day and also on the subsequent $5 \mathrm{~d}$ was determined. The average feeding rate resulting from sampling on $2 \mathrm{~d}$ and taking the average was calculated by combining the feeding rate on the day of sampling with that found on one of the subsequent days. This gave a total of 5 different estimates based on $2 \mathrm{~d}$ of sampling. A similar procedure was carried out to see the effect of sampling a population on 3 different days. The model was run 200 times and the results combined. If repeated sampling improved feeding rate estimates, then the average of 2 or more days would be closer to $100 \%$ than just $1 \mathrm{~d}$ alone. If the assumptions were true, the model also estimated the best subsequent days on which to sample. 
Table 1. Meganyctiphanes norvegica and Thysanoessa spp. Morphometrical and biochemical characterisation of krill, either freshly caught or at the end of their incubation period. Body length $(L)$ and dry weight $(W)$ data were analysed using the allometric equation: $W=\mathrm{a} L^{\mathrm{b}}$., with $\mathrm{n}$, the number of individuals. Carbon and nitrogen content are given as \% dry weight. All Thysanoessa spp. from experiments were combined for length-weight regression to increase sample size ( $\mathrm{n}=14)$

\begin{tabular}{|c|c|c|c|c|c|c|c|c|c|c|c|c|}
\hline \multirow[t]{2}{*}{ Species } & \multirow[t]{2}{*}{ Food } & \multirow[t]{2}{*}{$\mathrm{n}$} & \multirow[t]{2}{*}{$\begin{array}{l}\text { Length } \\
\text { (mm) }\end{array}$} & \multirow[t]{2}{*}{$\begin{array}{l}\text { Weight } \\
\text { (mg) }\end{array}$} & \multicolumn{3}{|c|}{$\begin{array}{l}\text { Length-weight } \\
\text { relationship }\end{array}$} & \multirow[t]{2}{*}{$\begin{array}{c}\mathrm{C} \text { content } \\
(\%)\end{array}$} & \multirow[t]{2}{*}{$\begin{array}{c}\mathrm{N} \text { content } \\
(\%)\end{array}$} & \multirow[t]{2}{*}{$\mathrm{C}: \mathrm{N}$} & \multirow[t]{2}{*}{$\begin{array}{l}\delta^{15} \mathrm{~N} \\
(\%)\end{array}$} & \multirow[t]{2}{*}{$\begin{array}{l}\delta^{13} \mathrm{C} \\
(\%)\end{array}$} \\
\hline & & & & & $\mathrm{a}$ & $\mathrm{b}$ & $\mathrm{R}^{2}$ & & & & & \\
\hline \multicolumn{13}{|l|}{ Field } \\
\hline M. norvegica & & 20 & $7.7 \pm 1.9$ & $1.4 \pm 1.0$ & 0.0044 & 2.7684 & 0.91 & $43.6 \pm 5.4$ & $11.5 \pm 1.3$ & $4.3 \pm 0.1$ & $11.9 \pm 0.3$ & $-13.9 \pm 0.4$ \\
\hline Thysanoessa spp & & 14 & $9.9 \pm 2.6$ & $3.1 \pm 3.4$ & 0.0006 & 3.6577 & 0.95 & $47.3 \pm 3.0$ & $11.0 \pm 1.1$ & $5.1 \pm 0.7$ & $12.0 \pm 0.3$ & $-15.1 \pm 1.1$ \\
\hline \multicolumn{13}{|l|}{ Experiments } \\
\hline M. norvegica & 100 nauplii & 10 & $11.3 \pm 1.2$ & $3.8 \pm 1.4$ & 0.0022 & 3.0766 & 0.81 & $40.2 \pm 2.1$ & $11.3 \pm 0.6$ & $4.2 \pm 0.2$ & & \\
\hline M. norvegica & 300 nauplii & 8 & $10.6 \pm 2.1$ & $3.7 \pm 1.9$ & 0.002 & 3.1456 & 0.95 & $43.4 \pm 3.0$ & $11.7 \pm 0.8$ & $4.3 \pm 0.4$ & & \\
\hline M. norvegica & Fish food & 28 & $10.2 \pm 1.7$ & $3.4 \pm 1.6$ & 0.0035 & 2.9251 & 0.96 & $41.5 \pm 4.4$ & $11.4 \pm 1.2$ & $4.3 \pm 0.1$ & & \\
\hline Thysanoessa spp. & 100 or 300 & 8 & $9.9 \pm 0.7$ & $3.5 \pm 2.5$ & & & & $48.6 \pm 4.4$ & $11.5 \pm 1.1$ & $5.0 \pm 0.5$ & & \\
\hline Thysanoessa spp. & $\begin{array}{l}\text { nauplii } \\
\text { Fish food }\end{array}$ & 6 & $8.6 \pm 0.8$ & $1.3 \pm 0.5 \mathrm{~J}$ & 0.0002 & 4 & 3 & $44.7 \pm 1.2$ & $11.4 \pm 0.3$ & $4.5 \pm 0.1$ & & \\
\hline
\end{tabular}

Table 2. Meganyctiphanes norvegica and Thysanoessa spp. Results of the Kolmogorov-Smirnov 1-sample test to assess moulting synchrony for the first 4 moult cycles (MC). The null hypothesis that moulting occurred equally over an 8,9 or $10 \mathrm{~d}$ period, depending on the mean length of the moult cycle, has to be rejected if $d_{i} \geq d_{\max }$. The difference between the observed cumulative moulting frequency and the expected cumulative moulting frequency, $d_{i}$, has been calculated for the mean length of the moult cycle, to the nearest day. The test statistic, $d_{\max }$, has critical values depending on the number of individuals (n) and the length of the moult cycle (d). Values given in bold indicate moulting synchrony $(p \leq 0.05)$

\begin{tabular}{|c|c|c|c|c|}
\hline $\begin{array}{l}\text { Moult } \\
\text { cycle }\end{array}$ & $\begin{array}{l}\text { Mean length } \\
\text { of MC (d) }\end{array}$ & $\begin{array}{l}\text { Applied length } \\
\text { of MC }\end{array}$ & $d_{i}$ & $\mathrm{~d}_{\max }$ \\
\hline \multicolumn{5}{|c|}{ M. norvegica (all, $\mathrm{n}=49$ ) } \\
\hline 1st & 8.4 & 8 & 16.6 & 9.1 \\
\hline 2nd & 8.8 & 9 & 4.6 & 9.5 \\
\hline 3rd & 9.1 & 9 & 7.2 & 9.5 \\
\hline 4 th & 9.5 & 9 & 3.7 & 9.5 \\
\hline \multicolumn{5}{|c|}{ M. norvegica (<10 mg, $\mathrm{n}=16)$} \\
\hline 1st & 8.0 & 8 & 8.0 & 6.0 \\
\hline 2nd & 8.1 & 8 & 4.0 & 6.0 \\
\hline 3rd & 8.2 & 8 & 6.0 & 6.0 \\
\hline 4 th & 9.0 & 9 & 4.9 & 5.5 \\
\hline \multicolumn{5}{|c|}{ M. norvegica (10-20 mg, $\mathrm{n}=13$ ) } \\
\hline 1st & 8.3 & 8 & 2.1 & 5.2 \\
\hline 2nd & 8.6 & 9 & 2.9 & 4.9 \\
\hline 3rd & 8.8 & 9 & 2.1 & 4.9 \\
\hline 4 th & 9.1 & 9 & 1.4 & 4.9 \\
\hline \multicolumn{5}{|c|}{ M. norvegica $(20-40 \mathrm{mg}, \mathrm{n}=20)$} \\
\hline 1 st & 9.2 & 9 & 6.1 & 6.1 \\
\hline 2nd & 9.6 & 10 & 4.0 & 6.0 \\
\hline 3rd & 10.0 & 10 & 3.0 & 6.0 \\
\hline 4 th & 10.3 & 10 & 2.8 & 6.0 \\
\hline \multicolumn{5}{|c|}{ Thysanoessa spp. (all, $\mathrm{n}=14$ ) } \\
\hline $1 \mathrm{st}$ & 7.9 & 8 & 4.8 & 5.5 \\
\hline 2nd & 7.6 & 8 & 2.5 & 5.5 \\
\hline 3rd & 7.8 & 8 & 3.5 & 5.5 \\
\hline 4th & 8.4 & 8 & 3.3 & 5.5 \\
\hline
\end{tabular}

\section{RESULTS}

\section{Morphometrical and biochemical characteristics}

Freshly caught specimens of Meganyctiphanes norvegica and Thysanoessa spp. spanned a similar range of body length and dry weight (Table 1). Species differed slightly in their length-weight relationship, $\mathrm{C}: \mathrm{N}$ ratio and $\delta^{13} \mathrm{C}$ value, but the $\mathrm{N}$ content and $\delta^{15} \mathrm{~N}$ values were very similar. Thus, the increase in dry weight with increasing body length was more pronounced in Thysanoessa spp. than in M. norvegica. Further, Thysanoessa spp. had higher $\mathrm{C}$ content and $\mathrm{C}: \mathrm{N}$ ratios but lower $\delta^{13} \mathrm{C}$ values, which indicates a higher lipid content. The $\delta^{15} \mathrm{~N}$ values of the larvae/ early postlarvae of both species were similar, while adult $M$. norvegica, sampled at the same time, had higher $\delta^{15} \mathrm{~N}$ values $(13.0 \pm 0.4 \%$, $\mathrm{n}=20)$. Even though a number of factors may confound interpretation of isotope data, higher $\delta^{15} \mathrm{~N}$ values usually suggest a higher trophic position (Peterson \& Fry 1987, Schmidt et al. 2003). Experimental animals did not differ from freshly caught krill in their length-weight relationship, or C and $\mathrm{N}$ contents (Table 1 ).

\section{Intermoult periods and moulting synchrony}

The intermoult periods of Meganyctiphanes norvegica ranged from 7 to $12 \mathrm{~d}$, showing differences between individuals and between consecutive moults. The smallest individuals (less than $10 \mathrm{mg}$ wet weight) mostly shed their moults after 8 (51\% of occasions) or $9 \mathrm{~d}(36 \%)$. Individuals of 10 to $20 \mathrm{mg}$ wet weight had an average intermoult period of $9 \mathrm{~d}(53 \%)$, but about $30 \%$ of all moults were shed after $8 \mathrm{~d}$. The largest indi- 


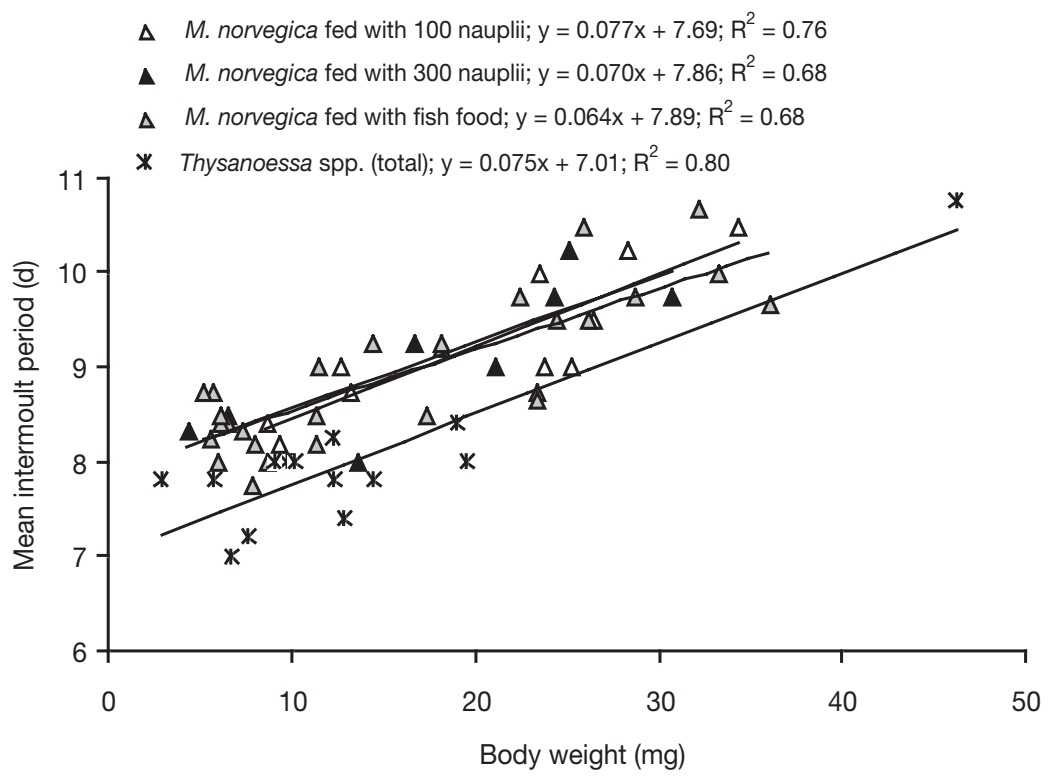

Fig. 1. Meganyctiphanes norvegica and Thysanoessa spp. Effect of body wet weight on the mean intermoult period of individual krill. All relationships were significant $(\mathrm{p}<0.05$, linear regression)

viduals (20 to $40 \mathrm{mg}$ wet weight) usually moulted after either 9 or $10 \mathrm{~d}(80 \%)$ and sometimes after $11 \mathrm{~d}(15 \%)$. Although intermoult period varied with body size (Fig. 1), diet did not have any further effect. The same held true for the feeding rate: for $M$. norvegica fed with Artemia salina nauplii, 44\% of the variability in the intermoult period was explained by body weight $(p<0.001)$ but none of it by different daily ration $(p=0.613$, multiple regression).

The mean intermoult period of Thysanoessa spp. was about $1 \mathrm{~d}$ shorter than for similar sized Meganyctiphanes norvegica $(p=0.0012$, Tukey's HSD test). Moulting usually occurred after $8 \mathrm{~d}$ (52\% of occasions), but $23 \%$ of all moults were shed after $7 \mathrm{~d}$. In line with results for $M$. norvegica, the average intermoult period of Thysanoessa spp. increased with body weight (Fig. 1).

The moulting activity did not show a directional change over the experimental period, but varied on a day-to-day basis. Both Meganyctiphanes norvegica and Thysanoessa spp. showed peaks of moulting activity every 7 to $10 \mathrm{~d}$, with 30 to $55 \%$ of the individuals moulting within $48 \mathrm{~h}$ of each other (Fig. 2). It was mainly during the first moult cycle that the distribution of moulting events was significantly (M. norvegica) or nearly significantly (Thysanoessa spp.) different from a random distribution (Table 2). Synchrony was strongest in the smallest size fraction of $M$. norvegica (Fig. 3, Table 2).

\section{Feeding rates in treatments with Artemia salina nauplii}

Overall, feeding rates of Meganyctiphanes norvegica and Thysanoessa spp. remained fairly constant over the experimental period covering 5 to 6 consecutive moulting events, but differed among treatments, individuals and days of the moult cycle (Fig. 4, Table 3). Both M. norvegica and Thysanoessa spp. showed higher feeding rates when 300 instead of 100 nauplii were offered every day; rates were 113 \pm 22 nauplii ind.$^{-1} \mathrm{~d}^{-1}$ versus $69 \pm 13$ nauplii ind. ${ }^{-1} \mathrm{~d}^{-1}$ for $M$. norvegica and $92 \pm 48$ nauplii ind..$^{-1} \mathrm{~d}^{-1}$ versus $33 \pm 10$ nauplii ind.-.$^{-1} \mathrm{~d}^{-1}$ for Thysanoessa spp. (Fig. 4).

There was a significant positive relationship between mean feeding rate of individual Meganyctiphanes norvegica and body weight in the treatment with 300 nauplii $\left(\mathrm{R}^{2}=0.5911, \mathrm{p}=0.026, y=\right.$ $1.8298 x+80.431)$. This was not the case with 100 nauplii offered every day, and the lower mean feeding rates suggest food limitation at this food concen-


Fig. 2. Meganyctiphanes norvegica and Thysanoessa spp. Moulting activity (\% of total individuals) over the experimental period. Data are plotted on a daily basis (grey) and added for 2 consecutive days (black) 
tration $\left(\mathrm{R}^{2}=0.0919, y=0.4506 x+59.754\right)$. Thysanoessa spp. had lower feeding rates than $M$. norvegica of similar size, but the number of individuals was too small for statistical analyses.

\section{Moult cycle-related changes in feeding rates}

Feeding rates changed depending on the day of the moult cycle. This pattern of variation was consistent, irrespective of food concentration and krill species (Fig. 5). Compared to the mean feeding rate over the
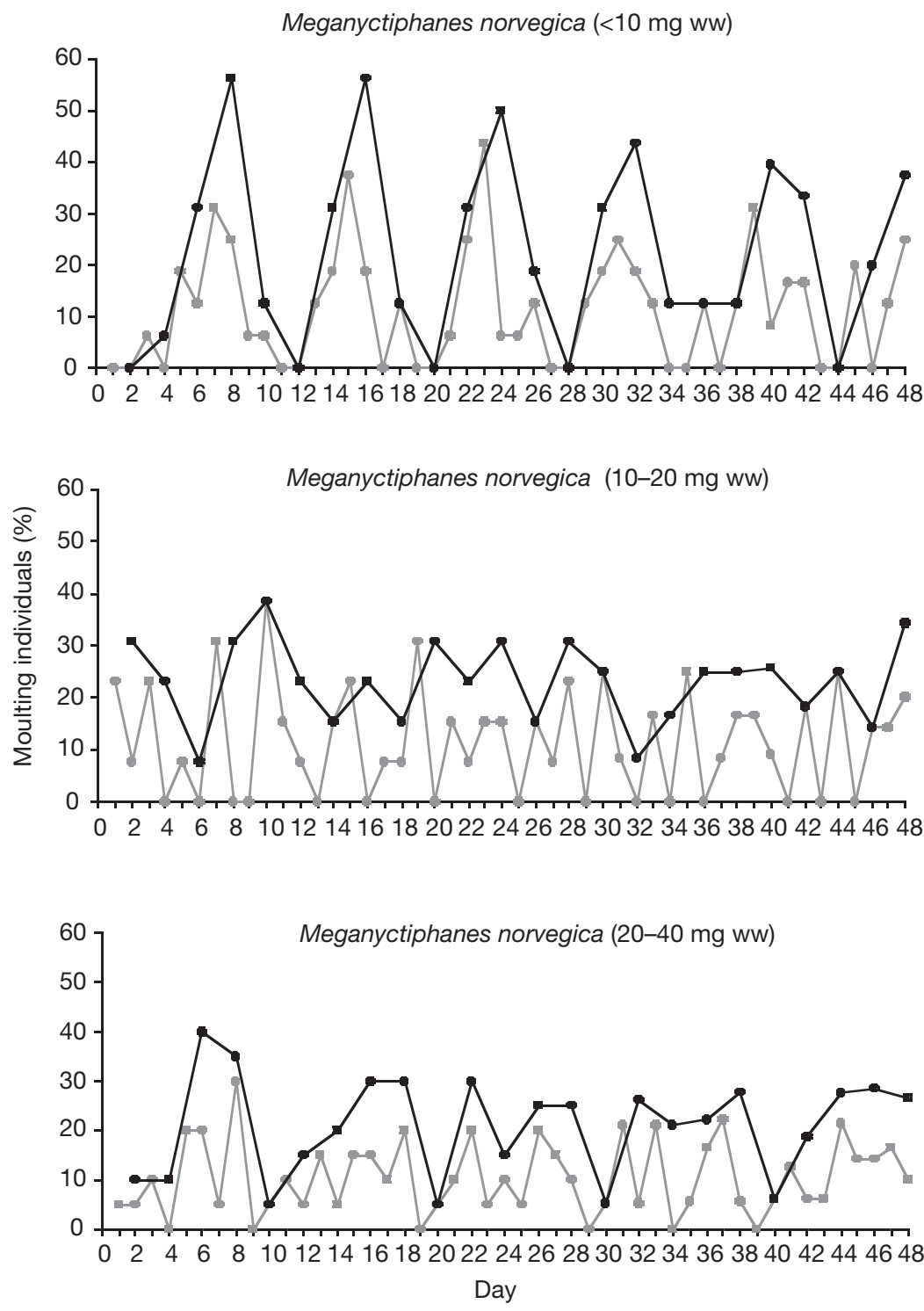

Fig. 3. Meganyctiphanes norvegica. Moulting activity (\% of individuals within a given size class) over the experimental period. Data are plotted on a daily basis (grey) and added for 2 consecutive days (black); ww: wet weight whole moult cycle, rates were reduced on average to $60-75 \%$ on the day before moulting ( $p<0.03$, 1 -sample $t$-test) and to about $90 \%$ on the moulting day. During the next 2 to $3 \mathrm{~d}$, feeding rates increased on average to $110-120 \%$ ( $\mathrm{p}<0.05,1$-sample $t$-test), but were similar to the mean for the rest of the moult cycle. The drop in feeding rate on the day before moulting was common to all individuals, but they differed in the length of time the reduction lasted for. Some individuals also had low feeding rates on the moulting day, while others showed moderate or even sharply increased food intake during the moulting day.

Moulting-induced differences in feeding rates of Meganyctiphanes norvegica were more pronounced in the treatment with 300 nauplii than in that with 100 nauplii ( $p=0.0159$, Tukey's HSD test). Before and after moulting, feeding rates differed by $74 \pm 25 \%$ of the mean in the treatment with 300 nauplii and by $46 \pm 14 \%$ in the treatment with 100 nauplii.

\section{Faecal pellet production in treatments with particulate fish food}

Meganyctiphanes norvegica feeding on particulate fish food produced on average $149 \pm 38$ pellets ind.$^{-1} \mathrm{~d}^{-1}$ of $0.38 \pm 0.05 \mathrm{~mm}$ length, which resulted in a mean defecation volume of $0.16 \pm$ $0.04 \mathrm{~mm}^{3}$ ind..$^{-1} \mathrm{~d}^{-1}$. Significant differences between individuals were seen in the length of faecal pellets, which increased with body size $\left(R^{2}=0.4875\right.$, $\mathrm{p}=0.0081, y=0.0365 x+1.5951)$, but not in number of pellets and defecation volume (Table 4). Faecal pellet production was consistent over 2 consecutive moult cycles, but varied with the day of the moult cycle (Fig. 6, Table 4). The number of faecal pellets and the defecation volume dropped on the moulting day and day after to about $50 \%$ of the mean value, but increased on average to $140-180 \%$ of the mean on Days 3 and 4 after moulting (Fig. 7). Differences in the length of faecal pellets were less pronounced, with a reduction to $75-90 \%$ of the mean value during the moulting day and day thereafter, and an increase to about $110 \%$ after moulting. 




Fig. 4. Meganyctiphanes norvegica and Thysanoessa spp. Mean feeding rates over the experimental period of about 6 to 7 wk. The moult cycle was divided in 4 periods: day before moulting and moulting day (0), Days 1 and 2 after moulting (2), Days 3 and 4 after moulting (4) and Days 5 and 6 after moulting (6). If the moult cycle was longer than $8 \mathrm{~d}$, additional days were included in the last 2 periods

\section{Maximum likelihood model; the effect of repeated sampling}

The potential error in feeding rates that would be made when sampling a synchronously moulting population depends on the prevailing moult stage within the population. Rates might deviate from the mean feeding rate over the whole moult cycle by up to $40 \%$ on the day before moulting and up to $25 \%$ on the day after moulting, but will match the mean feeding rate on other days (Fig. 5). In field situations, an investigator is often unaware of the dominant moult stage since its determination is time consuming and requires some practice. In these instances, an accuracy of, on average, no more than \pm 10 to $16 \%$ of the average feeding rate over the whole moult cycle can be expected, depending on food concentration (Table 5). However, if the same population is sampled twice on non-con- secutive days, the potential error can be reduced by at least $1 / 3$. Visiting a population 3 times can reduce the potential error by half.

\section{DISCUSSION}

Feeding studies of pelagic crustaceans have frequently addressed diurnal cycles and vertical migration, but very few have looked at the longer moult cycle. This is partly because pelagic crustaceans, such as euphausiids, are highly mobile, swim constantly to avoid sinking and move in swarms, and are thus expected to be little impaired by moulting. However, this study has shown that feeding rates of euphausiids vary clearly with the moult cycle. Together with the fact that moulting can be partially synchronised, this has consequences for the interpretation both of field data on gut content and laboratory feeding experiments. The target organisms of this study were the important, but rarely examined, early developmental stages of Meganyctiphanes norvegica and Thysanoessa spp. We therefore (1) discuss basic data on their intermoult period, (2) compare moult cycle related changes in feeding rates of euphausiids with those of decapods, (3) discuss the phenomenon of moulting synchrony, and finally (4) give some implications of our findings for field sampling.

\section{Intermoult period}

The 2 components that determine the pattern of crustacean growth are the intermoult period and the growth increment per moult. An effect of temperature and body size on the intermoult period has been shown repeatedly, but there are conflicting results on the effect of food (reviewed in Hartnoll 1982). Some studies on euphausiids suggest that a deficit in food quality or quantity reduces the increment per moult but does not affect the intermoult period (Lasker 1966, Fowler et al. 1971), while others also found a lengthening of the intermoult period (Le Roux 1974, Pillar 1985, Buchholz 1991).

Table 3. Meganyctiphanes norvegica and Thysanoessa spp. Comparison of differences in feeding rates (nauplii ind. ${ }^{-1} \mathrm{~d}^{-1}$ )

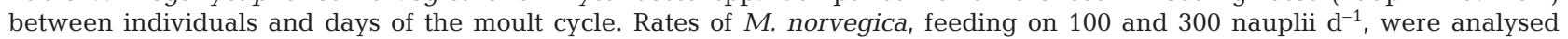
separately, while for Thysanoessa spp. data from both treatments were combined to increase sample size

\begin{tabular}{|c|c|c|c|c|c|c|c|c|c|}
\hline \multirow[b]{2}{*}{ Source } & \multicolumn{3}{|c|}{ M. norvegica (100 nauplii) } & \multicolumn{3}{|c|}{ M. norvegica (300 nauplii) } & \multicolumn{3}{|c|}{ Thysanoessa spp. (100 and 300 nauplii) } \\
\hline & df & $F$ & $\mathrm{p}$ & $\mathrm{df}$ & $F$ & $\mathrm{p}$ & $\mathrm{df}$ & $F$ & $\mathrm{p}$ \\
\hline Individuals & 9 & 13.03 & 0.0001 & 7 & 5.00 & 0.002 & 7 & 21.79 & 0.0001 \\
\hline Days of moult cycle & 3 & 16.54 & 0.0001 & 3 & 6.45 & 0.003 & 3 & 4.00 & 0.024 \\
\hline
\end{tabular}



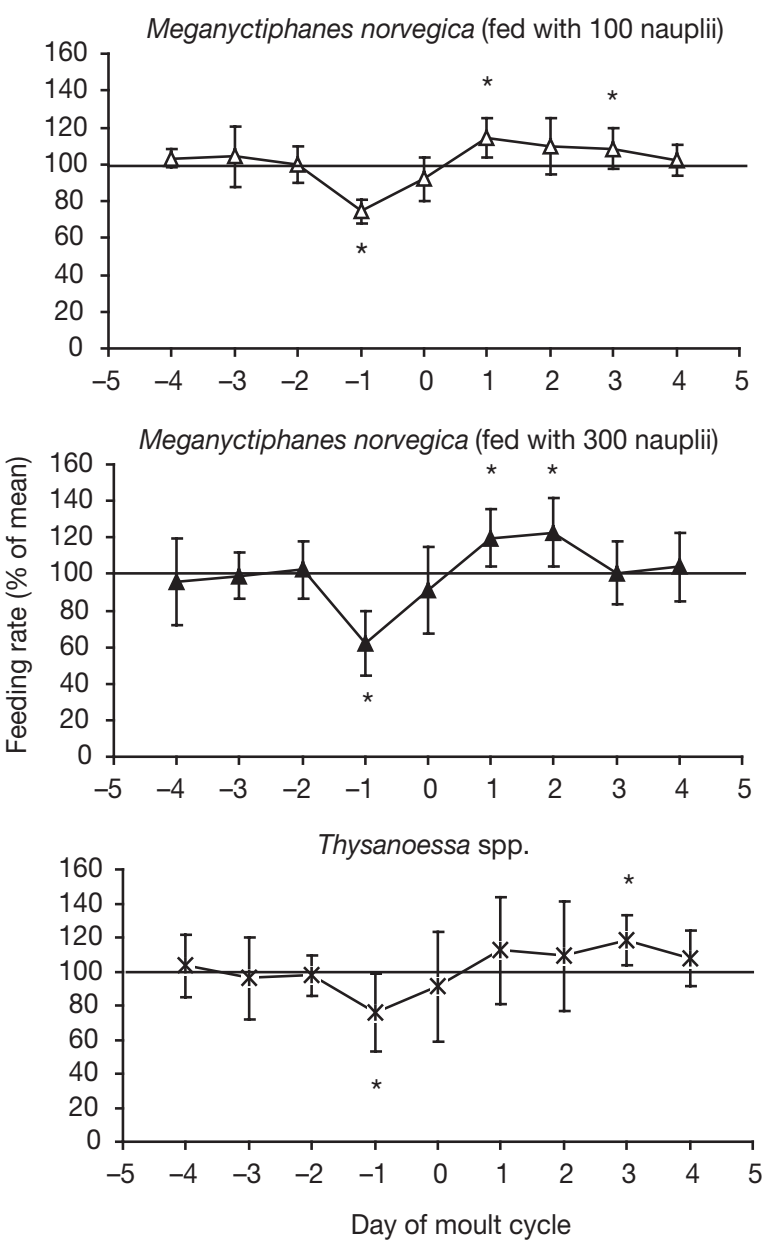

Fig. 5. Meganyctiphanes norvegica and Thysanoessa spp. The effect of moulting on feeding activity. For each krill the mean feeding rate on a particular day of the moult cycle was compared with that over the whole experimental period. The values (mean $\pm 1 \mathrm{SD}$ ) represent all individuals per treatment for $M$. norvegica and combined results from treatments with 100 and 300 nauplii for Thysanoessa spp. *: significant reduction or increase in feeding rates $(\mathrm{p}<0.05,1$-sample $t$-test)

In the present study, the intermoult period of larval Meganyctiphanes norvegica increased with body weight, but was not sensitive to the food regime. This suggests that the quantitative difference between 100 and 300 Artemia salina nauplii, and the qualitative difference between $A$. salina and particulate commercial fish food were of minor importance in determining the intermoult period in our experiments. Likewise, Le Roux (1974) found that larval $M$. norvegica from the Mediterranean had an intermoult period of 4 to $5 \mathrm{~d}$ when fed either with a pure diet of $A$. salina nauplii or a mixture of $A$. salina nauplii and 2 algae species. However, the intermoult period increased when only algae were given, underlining the value of an animal component in the diet of early developmental stages of M. norvegica (Le Roux 1974). Larvae of another euphausiid, Nyctiphanes capensis, had a slightly longer intermoult period when fed with pure algae Phaeodactylum tricornutum or copepod nauplii, while no differences were seen with pure $A$. salina nauplii, the algae Tetraselmis chuii or various mixtures (Pillar 1985). The effect of food concentration seems to be similar to that of food quality, altering the intermoult period only when in a clear deficit (Ikeda \& Thomas 1987). This might explain why temperature and body size, but not food, are usually assumed to be the major factors determining the intermoult period (Mauchline 1980, Nicol 2000).

Our observations that intermoult periods were $\sim 8 \mathrm{~d}$ for larvae/early postlarvae of Thysanoessa spp. and 9 d for Meganyctiphanes norvegica agree well with results from previous studies, when accounting for different temperature or body size (Paranjape 1967 , Fowler et al. 1971, Le Roux 1974, Sameoto 1976, Dalpadado \& Ikeda 1989).

\section{Moult cycle-related changes in feeding rate}

There is conflicting evidence on the effects of moulting on the feeding activity of euphausiids. Lasker (1966) first noted that Euphausia pacifica ingested fewer nauplii on the day of ecdysis and suggested that moulting impairs feeding. Likewise, Paranjape (1967) concluded from faecal pellet production of euphausiids that feeding decreases on the days before and during ecdysis, but increases sharply afterwards. On the other hand, Buchholz (1989) found no reduction in the diges-



Days of moult cycle

Fig. 6. Meganyctiphanes norvegica. Mean number (ם) and length of faecal pellets $(\square)$ over an experimental period of about 2 wk 
Table 4. Meganyctiphanes norvegica. Comparison of differences in number of faecal pellets (ind. ${ }^{-1} \mathrm{~d}^{-1}$ ), length of faecal pellets $(\mathrm{mm})$ and defecation volume $\left(\mathrm{mm}^{3}\right.$ ind. $\left.{ }^{-1} \mathrm{~d}^{-1}\right)$ between individuals and days of the moult cycle

\begin{tabular}{|lccccccccc|}
\hline & \multicolumn{3}{c}{ Number of faecal pellets } & \multicolumn{3}{c|}{ Length of faecal pellets } & \multicolumn{3}{c|}{ Defecation volume } \\
Source & $\mathrm{df}$ & $F$ & $\mathrm{p}$ & $\mathrm{df}$ & $F$ & $\mathrm{p}$ & $\mathrm{df}$ & $F$ & $\mathrm{p}$ \\
\hline Individuals & 7 & 2.18 & 0.093 & 7 & 3.39 & 0.02 & 7 & 1.58 \\
Days of moult cycle & 3 & 7.61 & 0.002 & 3 & 4.61 & 0.015 & 3 & 8.78 \\
\end{tabular}

tive enzyme activity of Euphausia superba around ecdysis, which led him and Priddle et al. (1990) to conclude that krill behave differently from benthic decapods in that their activity is little affected by moulting and their feeding is only interrupted for a very short time. However, none of the above studies quantified changes in feeding or defecation rates over the whole moult cycle.

Our results for late furcilia and early postlarvae of Meganyctiphanes norvegica and Thysanoessa spp. suggest that daily feeding rates of krill can be significantly affected by the moult cycle. The succession of events, with lowest feeding rates before ecdysis and highest rates soon afterwards, mirrors the pattern in decapods and isopods (Chittleborough 1975, Strong \& Daborn 1980, Lipcius \& Herrnkind 1982, Hill \& Wassenberg 1992, Anger 2001). Forming the new and detaching the old exoskeleton will, to some extent, affect peripheral, sensory neural pathways and muscular insertions, and therefore the ability to catch, handle and macerate food items. Shedding of the entire chitinous lining of the foregut has been described for decapods (Passano 1960) and euphausiids (Ikeda et al. 1984), and essentially stops food passage and digestion. Elevated ingestion rates directly after moulting might represent compensation for previous metabolic losses and uptake of minerals to harden the exoskeleton rapidly (Hill \& Wassenberg 1992, de Lestang et al. 2000).

Thus, euphausiids and decapods do not differ in their basic responses during moulting, but might vary in the actual duration of events. For example, in a subadult lobster Panulirus argus with an intermoult period of $\sim 63 \mathrm{~d}$, the drop in the feeding rate started $\sim 8 \mathrm{~d}$ before ecdysis, no feeding was observed for at least $1 \mathrm{~d}$ around ecdysis and the period of increased feeding after ecdysis lasted for $\sim 10 \mathrm{~d}$ (from data in Lipcius \& Herrnkind 1982). By comparison, the intermoult period of larval Meganyctiphanes norvegica was only $9 \mathrm{~d}$, of which $1 \mathrm{~d}$ was characterised by reduced feeding rates and $2 \mathrm{~d}$ by enhanced feeding rates. Thus, the $24 \mathrm{~h}$ period over which feeding rates are usually integrated, represents a shorter proportion of the total moult cycle in $P$. argus than in $M$. norvegica. As a consequence, daily feeding rates of $P$. argus can differ greatly from the mean feeding rate (up to $100 \%$ ), while those of $M$. norvegica differ much less $(\sim 30 \%)$. On the day of ecdysis, the feed- ing rate of $M$. norvegica was not zero but close to the mean, probably because feeding only stopped for a fraction of that day and thereafter a period of high feeding activity started.
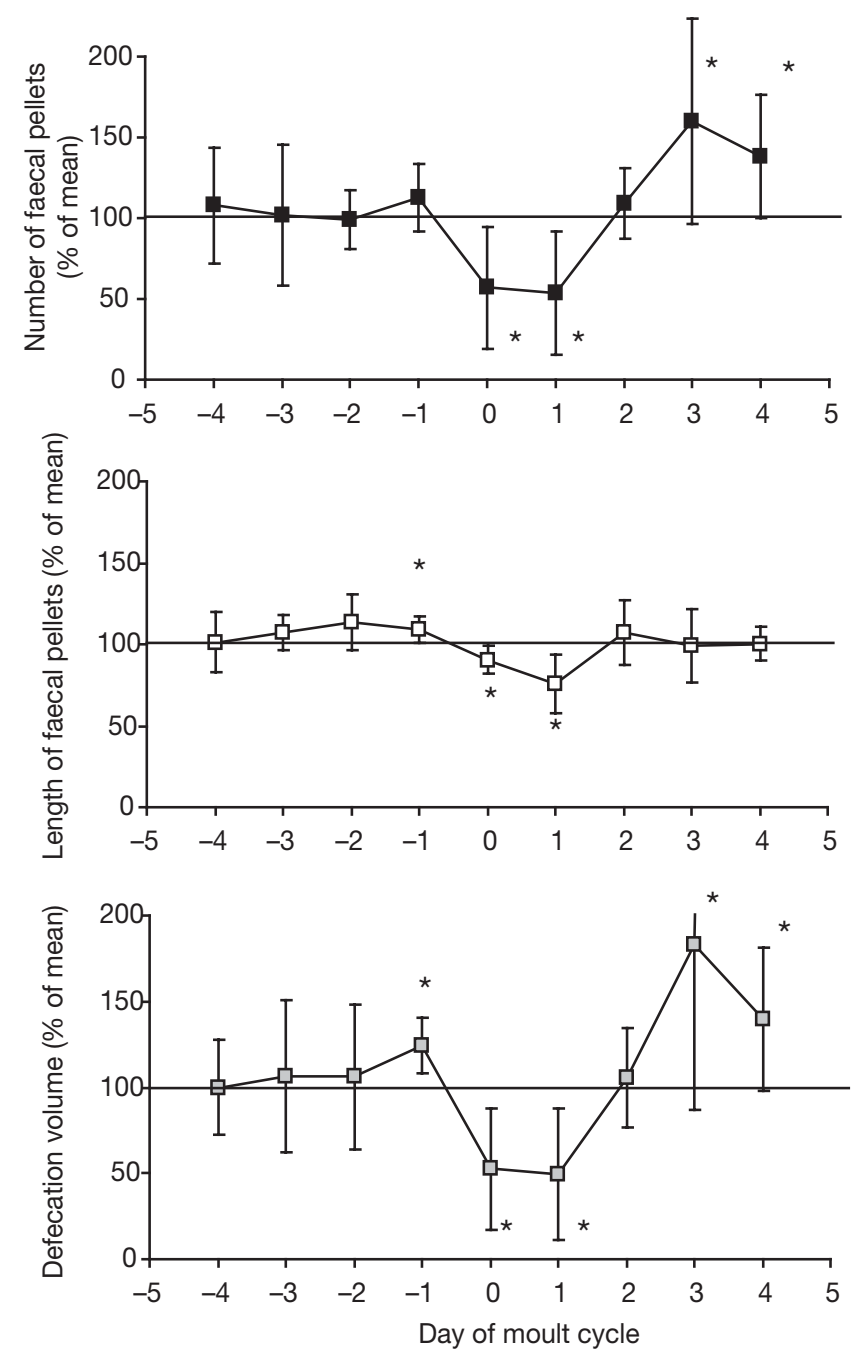

Fig. 7. Meganyctiphanes norvegica. The effect of moulting on the number and length of faecal pellets, and the defecation volume. For each krill the mean number, length and volume of faecal pellets on a particular day of the moult cycle was compared with the mean values over 2 moult cycles. Values represent all individuals (mean $\pm 1 \mathrm{SD}$ ). * : indicate significant reduction or increase in parameters ( $\mathrm{p}<0.05,1$-sample $t$-test) 
A synthesis of data across euphausiids, decapods and isopods confirms that moulting events are more strongly reflected in daily feeding rates when the inter-

Table 5. Meganyctiphanes norvegica and Thysanoessa spp. The probable error (coefficient of variation) in feeding rates that would be made when sampling a synchronously moulting population once, twice or on 3 occasions. Where a population was theoretically sampled either twice or 3 times, the best estimate of feeding rate was assumed to be the average of these particular observations



moult period is longer (Table 6). This is not only true for different species and developmental stages, but also for the same stage reared at different temperatures. The feeding rate of megalopa larvae of the crab Carcinus maenas was zero on the day before ecdysis when the intermoult period was long $\left(21 \mathrm{~d}\right.$ at $\left.12{ }^{\circ} \mathrm{C}\right)$, but dropped to only $60 \%$ of the mean when the intermoult period was short (8 d at $25^{\circ} \mathrm{C}$ ) (Dawirs \& Dietrich 1986). Food concentration is another factor that alters the reduction and subsequent increase in feeding rates around ecdysis. Our experiments showed that, with excess food, daily feeding rates of Meganyctiphanes norvegica before and after moulting differed by about

Table 6. Comparison of moult cycle-related changes in daily feeding rates for various species of euphausiid, isopod and decapods. Minimum and maximum feeding rates ( $\%$ of mean feeding rate over the whole moult cycle) were calculated from data given in literature searched. The feeding rate on a particular day of the moult cycle was classed as differing significantly from the mean feeding rate over the whole moult cycle, when its standard deviation (SD) did not cover the mean value. $n_{i}$ number of replicates, IMP; intermoult period

\begin{tabular}{|c|c|c|c|c|c|c|}
\hline Species/Stage & $\mathrm{n}$ & IMP (d) & $\begin{array}{l}\text { Food source/ } \\
\text { concentration/Temp. }\left({ }^{\circ} \mathrm{C}\right)\end{array}$ & $\begin{array}{l}\text { Feeding } \\
(\min )\end{array}$ & $\begin{array}{l}\text { rate }(\%) \\
\quad(\max )\end{array}$ & $\begin{array}{l}\text { Values differing } \\
\text { from mean }\end{array}$ \\
\hline \multicolumn{7}{|c|}{$\begin{array}{l}\text { Euphausiid Meganyctiphanes norvegica } \\
\text { (present study) }\end{array}$} \\
\hline Late furcilia larvae & 10 & 9 & Artemia sp./low conc. & 75 & 115 & $33 \%$ \\
\hline Late furcilia larvae & 8 & 9 & Artemia sp./high conc. & 60 & 123 & $33 \%$ \\
\hline \multicolumn{7}{|c|}{$\begin{array}{l}\text { Euphausiid Thysanoessa spp. } \\
\text { (present study) }\end{array}$} \\
\hline Late furcilia larvae & 8 & 9 & Artemia sp. & 76 & 118 & $22 \%$ \\
\hline \multicolumn{7}{|l|}{$\begin{array}{r}\text { Crab Hyas araneus } \\
\text { (Harms et al. 1991) }\end{array}$} \\
\hline Zoea II larvae & 20 & 13 & Artemia sp. & 46 & 137 & $\sim 50 \%$ \\
\hline Megalopa larvae & 20 & 28 & Artemia sp. & 48 & 192 & $\sim 50 \%$ \\
\hline \multicolumn{7}{|c|}{$\begin{array}{l}\text { Crab Carcinus maenas } \\
\text { (Dawirs \& Dietrich 1986) }\end{array}$} \\
\hline Megalopa larvae & 10 & 8 & Artemia sp. $/ 25^{\circ} \mathrm{C}$ & 60 & 147 & $\sim 25 \%$ \\
\hline Megalopa larvae & 10 & 10 & Artemia sp. $/ 18^{\circ} \mathrm{C}$ & 21 & 240 & $\sim 90 \%$ \\
\hline Megalopa larvae & 10 & 16 & Artemia sp. $/ 15^{\circ} \mathrm{C}$ & 8 & 279 & $\sim 70 \%$ \\
\hline Megalopa larvae & 10 & 21 & Artemia sp. $/ 12^{\circ} \mathrm{C}$ & 0 & 250 & $\sim 60 \%$ \\
\hline \multicolumn{7}{|c|}{$\begin{array}{l}\text { Rock lobster Jasus edwardsii } \\
\text { (Tong et al. 1997) }\end{array}$} \\
\hline Phyllosoma VI larvae & 10 & 16 & Artemia sp./low conc. & 58 & 104 & no SD \\
\hline Phyllosoma VI larvae & 10 & 15 & Artemia sp./medium conc. & 50 & 110 & no SD \\
\hline Phyllosoma VI larvae & 10 & 14 & Artemia sp./high conc. & 52 & 118 & no SD \\
\hline \multicolumn{7}{|c|}{$\begin{array}{l}\text { Spiny lobster Panulirus longipes } \\
\text { (Chittleborough 1975) }\end{array}$} \\
\hline Juvenile & 2 & $\sim 50$ & Abalone muscle & 0 & 325 & no SD \\
\hline \multicolumn{7}{|c|}{$\begin{array}{l}\text { Spiny lobster Panulirus argus } \\
\text { (Lipcius \& Herrnkind 1982) }\end{array}$} \\
\hline Subadult & 6 & 63 & Fiddler crab & 0 & 213 & $\sim 30 \%$ \\
\hline \multicolumn{7}{|l|}{$\begin{array}{l}\text { Isopod Idotea baltica } \\
\quad \text { (Strong \& Daborn 1980) }\end{array}$} \\
\hline Adult & 17 & 24 & Algae material & 19 & 146 & $\sim 50 \%$ \\
\hline \multicolumn{7}{|c|}{$\begin{array}{l}\text { Prawn Penaeus esculentus } \\
\text { (Hill \& Wassenberg 1992) }\end{array}$} \\
\hline Adult & 34 & 24 & Greentail prawn & 0 & 203 & $\sim 50 \%$ \\
\hline
\end{tabular}


$\pm 30 \%$ from the mean, while with lower food, rates differed by only $\pm 20 \%$. A similar tendency was seen for phyllosoma larvae of a lobster, Jasus edwardsii, also fed with different concentrations of Artemia sp. (Tong et al. 1997). Daily food consumption of decapod larvae did not alter over the moult cycle when food concentration or quality was limited (Harms et al. 1991, Tong et al. 1997). Furthermore, we found clear individual differences in response to moulting. Some krill, for instance, had reduced feeding rates on 3 consecutive days before ecdysis, while others only on $1 \mathrm{~d}$. Such individual variability has also been seen in lobster and prawns (Lipcius \& Herrnkind 1982, Wassenberg \& Hill 1984). About $30 \%$ of the prawns Penaeus esculentus continued feeding on the night of ecdysis (Wassenberg \& Hill 1984).

Comparing minimum and maximum feeding rates of various crustacean species (Table 6), it is clear that the effect of moulting on average daily feeding rates is less pronounced in larval Meganyctiphanes norvegica and Thysanoessa spp. than in juvenile and adult decapods, but is very similar to that in some decapod larvae and in an isopod species. Thus, there is no fundamental difference in feeding behaviour between euphausiids and decapods around ecdysis. This seems to be true not only for feeding, but for their general activity. Ecdysis within seconds has not only been observed for Euphausia superba (Buchholz 1991), but also in several prawn species, while lobsters often take more time (reviewed in Wassenberg \& Hill 1984). The prawn Penaeus esculentus is able to swim immediately after ecdysis (Wassenberg \& Hill 1984) and the lobster Panulirus argus also retains its neuromuscular coordination around ecdysis (Lipcius \& Herrnkind 1982). Sustained agility seems to be a critical feature of the moult cycle, not only in pelagic crustaceans but also in those decapods that moult in the presence of conspecifics and mate in the soft-shelled postmoult condition (Atema et al. 1979, Lipcius \& Herrnkind 1982).

\section{Synchronous moulting}

Synchronous moulting of euphausiids has been observed frequently, but authors debate whether it is an artefact caused by their capture (Clarke \& Morris 1983, Nicol 1989) or a common strategy in the field (Morris 1985, Tarling et al. 1999). However, an induction of moulting synchrony during capture of the animals seems unlikely, as spontaneous shedding of the exoskeleton as a fright response (Hamner et al. 1983) is only possible in those krill which are very close to ecdysis (Buchholz 1985).

In the present study, peaks of moulting activity were observed every $8 \mathrm{~d}$ for the smallest size class of Meganyctiphanes norvegica - which clearly suggests moulting synchrony. Larger $M$. norvegica and Thysanoessa spp. showed some tendency towards synchronous moulting during their first moult cycle in the laboratory, but lost this pattern later in the experiment. Unfortunately, we did not have enough freshly caught krill larvae to perform a moult-stage analysis; the ultimate proof of moulting synchrony in the field (Buchholz 1985, Nicol \& Stolp 1990). Applying this moult-stage technique, Tarling \& Cuzin-Roudy (2003), observed that female $M$. norvegica in the Clyde Sea spawn and moult synchronously throughout the reproductive season. Thus, eggs are released in pulses and distinct cohorts can develop. Such a mass occurrence of vulnerable developmental stages (egg, early larvae) might satiate the predator population and thereby reduce total losses in the prey population (Ims 1990). Similarly, synchronised moulting of the larvae might minimise predation and cannibalism during vulnerable stages of the moult cycle (Reaka 1976). Even though moulting or spawning synchrony seem to be most persistent in isolated M. norvegica populations inhabiting the Clyde Sea (Tarling \& Cuzin-Roudy 2003), Kattegat (Tarling et al. 1999) or Gullmarsfjord, it has also occasionally been found in Euphausia superba swarming in open waters (Buchholz et al. 1996, G. A. Tarling et al. unpubl. data).

\section{Implications for field studies on gut content and feeding rate}

Among the many factors that might dictate the feeding rates of euphausiids in the field, the effect of the moult cycle stage has rarely been examined. Only Priddle et al. (1990) linked variations in gut fullness of Euphausia superba swarms to individual characteristics such as body length, maturity stage and moult stage. Empty guts characterised $60 \%$ of krill just before moult and $30 \%$ of those just after, resulting in lower average gut fullness in these groups compared to other moult stages (Priddle et al. 1990). However, these groups comprised a small fraction of the population, and so moult stage accounted for only $4.2 \%$ of the total variation in gut fullness (Priddle et al. 1990). Our study suggests that moulting does not only cause an empty gut around ecdysis, but has an extended and rather complex effect on feeding. Thus, feeding rates might be significantly reduced or increased over a longer proportion of the moult cycle (Table 6), and the strength of the effect varies with food concentration and intermoult period.

Measuring ingestion rates is another method used to study krill feeding activity and food preferences (e.g. Atkinson et al. 2002). A common assumption here is 
that experiments with a few individuals chosen randomly from the field will provide a satisfactory estimate of energy consumption for an average member of the population. In some studies, moulting krill were excluded to reduce the variability of the results (Heyraud 1979, Ikeda \& Mitchell 1982). However, our study suggests that feeding rates could be biased even though ecdysis may not occur during the experiment. We found that, with a short intermoult period, rates deviated from the mean value mainly on the day before and after ecdysis.

Over- or underestimation of population feeding rates of up to $40 \%$ might occur when most of the krill are in the same moult stage and the population is sampled during a few days around moulting. Accurate moult staging requires time and practice, so the dominant moult stage in a population on the day of sampling is usually not determined. In these cases, measurements of feeding rates can be no more accurate than $\pm 15 \%$ (Table 5). Such an error in feeding rates might be of minor relevance compared to those inherent in experimental manipulation or carbon-conversion factors (Båmstedt et al. 2000). However, errors may be greater for synchronously moulting adults due to their longer intermoult period. If repeated sampling of a population is possible, ideally on 2 non-consecutive days, this will reduce the effect of the moult cycle by one-third and, therefore, help to gain more precise population feeding rates or bioenergetic models for individual krill.

Acknowledgements. The experimental work at Kristineberg Marine Research Station was funded by the EU Large Scale Facility Programme. We thank the captain and crew of 'Arne Tiselius' for collecting krill and M. Thomasson for supervising species identification. M. Voss, I. Liskow and B. Deutsch provided logistical support for our trip to Kristineberg. P. Rothery helped with statistical analysis. We are grateful to A. Clarke, D. Pond, R. Shreeve and the 4 anonymous referees for valuable comments on the manuscript. The study was funded by the German Federal Ministry of Education and Research (03PL025C) and by the German Research Council (DFG Schm 1721/1).

\section{LITERATURE CITED}

Anger K (2001) The biology of decapod crustacean larvae. A.A. Balkema Publishers, Tokyo

Antezana T, Ray K, Melo C (1982) Trophic behaviour of Euphausia superba Dana in laboratory conditions. Polar Biol 1:77-82

Atema J, Jacobson S, Karnofsky E, Olesko-Szuts S, Stein L (1979) Pair formation in the lobster, Homarus americanus: behavioral development, pheromones and mating. Mar Behav Physiol 6:277-296

Atkinson A, Meyer B, Stübing D, Hagen W, Schmidt K, Bathmann UV (2002). Feeding and energy budgets of Antarctic krill Euphausia superba at the onset of winter. II. Juveniles and adults. Limnol Oceanogr 47:953-966

Båmstedt U, Gifford DJ, Irigoien X, Atkinson A, Roman M
(2000) Feeding. In: Harris R, Wiebe P, Lenz J, Skjødal HR, Huntley M (eds) ICES zooplankton methodological manual. Academic Press, San Diego, CA. p 297-399

Bernardez C, Freire J, Gonzalez-Gurriaran E (2000) Feeding of the spider crab Maja quinado in rocky subtidal areas of the Ria de Arousa (north-west Spain). J Mar Biol Assoc UK 80:95-102

Buchholz F (1985) Moult and growth in euphausiids. In: Siegfried WR, Condy PR, Laws RM (eds) Antarctic nutrient cycles and food webs. Springer-Verlag, Heidelberg, p 339-345

Buchholz F (1989) Moulting cycle and seasonal activities of chitinolytic enzymes in the integument and digestive tract of the Antarctic krill, Euphausia superba. Polar Biol 9:311-317

Buchholz F (1991) Moult cycle and growth of Antarctic krill Euphausia superba in the laboratory. Mar Ecol Prog Ser 69:217-229

Buchholz F, Watkins JL, Priddle J, Morris DJ, Ricketts C (1996) Moult in relation to some aspects of reproduction and growth in swarms of Antarctic krill, Euphausia superba. Mar Biol 127:201-208

Carvalho PSM, Phan NV (1998) Oxygen consumption and ammonia excretion during the moulting cycle in the shrimp Xiphopenaeus kroyeri. Comp Biochem Physiol A 119:839-844

Chang ES (1995) Physiological and biochemical changes during the molt cycle in decapod crustaceans: an overview. J Exp Mar Biol Ecol 193:1-14

Chittleborough RG (1975) Environmental factors affecting growth and survival of juvenile western rock lobster, Panulirus longipes (Milne-Edwards). Aust J Mar Freshw Res 26:177-196

Clarke A, Morris DJ (1983) Towards an energy budget for krill: the physiology and biochemistry of Euphausia superba Dana. Polar Biol 2:69-86

Dalpadado P, Ikeda T (1989) Some observations on moulting, growth and maturation of krill (Thysanoessa inermis) from the Barents Sea. J Plankton Res 11:133-139

Dalpadado P, Ellertsen B, Melle W, Dommasnes A (2000) Food and feeding conditions of Norwegian springspawning herring (Clupea harengus) through its feeding migrations. ICES J Mar Sci 57: 843-857

Dawirs RR, Dietrich A (1986) Temperature and laboratory feeding rates in Carcinus maenas L. (Decapoda: Portunidae) larvae from hatching through metamorphosis. J Exp Mar Biol Ecol 99:133-147

de Lestang S, Platell ME, Potter IC (2000) Dietary composition of the blue swimmer crab Portunus pelagicus L. Does it vary with body size and shell state and between estuaries? J Exp Mar Biol Ecol 246:241-257

Einarsson H (1945) Euphausiacea I. Northern Atlantic species. Dana-Rep Carlsberg Found 27:1-185

Falk-Petersen S, Hopkins CCE (1981) Ecological investigations on the zooplankton community of Balsfjorden, northern Norway: Population dynamics of the euphausiids Thysanoessa inermis, T. raschii. J Plankton Res 3:177-192

Fowler SW, Small LF, Keckes S (1971) Effects of temperature and size on moulting of euphausiid crustaceans. Mar Biol 11:45-51

Hamner WM, Hamner PP, Strand SW, Gilmer RW (1983) Behavior of antarctic krill, Euphausia superba: chemoreception, feeding, schooling, and molting. Science 220: 433-435

Harms J, Anger K, Klaus S, Seeger B (1991) Nutritional effects on ingestion rate, digestive enzyme activity, growth, and biochemical composition of Hyas araneus L. (Decapoda: 
Majidae) larvae. J Exp Mar Biol Ecol 145: 233-265

Hartnoll RG (1982) Growth. In: Abele LG (ed) The biology of Crustacea 2; embryology, morphology and genetics. Academic Press, New York, p 11-196

Heyraud M (1979) Food ingestion and digestive transit time in the euphausiid Meganyctiphanes norvegica as a function of animal size. J Plankton Res 1:301-311

Hilborn R, Mangel M (1997) The ecological detective. Monographs in population biology 28. Princeton University Press. Princeton, NJ

Hill BJ, Wassenberg TJ (1992) Preferences and amount of food eaten by the prawn Penaeus esculentus over the moult cycle. Aust J Mar Freshw Res 43:727-735

Ikeda T, Mitchell AW (1982) Oxygen uptake, ammonium excretion and phosphate excretion by krill and other Antarctic zooplankton in relation to their body size and chemical composition. Mar Biol 71:283-298

Ikeda T, Thomas PG (1987) Moulting interval and growth of juvenile Antarctic krill fed different concentrations of the diatom Phaenodactylum tricornutum in the laboratory. Polar Biol. 7:339-343

Ikeda T, Nash GV, Thomas PG (1984) An observation of discarded stomach with exoskeleton moult from Antarctic krill Euphausia superba Dana. Polar Biol 3:241-244

Ims RA (1990) The ecology and evolution of reproductive synchrony. Trends Ecol Evol 5:135-140

Kirkwood JM (1982) A guide to the Euphausiacea of the southern ocean. ANARE Res Notes 1:1-45

Lasker R (1966) Feeding, growth, respiration and carbon utilization of a euphausiid shrimp. J Fish Res Board Can 23:1291-1317

Le Roux A (1974) Observations sur le developpement larvaire de Meganyctiphanes norvegica (Crustacea: Euphausiacea) au laboratoire. Mar Biol 26:45-56

Lipcius RN, Herrnkind WF (1982) Molt cycle alterations in behaviour, feeding and diel rhythms of a decapod crustacean, the Spiny lobster Panulirus argus. Mar Biol 68:241-252

Mauchline J (1980) The biology of mysids and euphausiids. Adv Mar Biol 18:1-681

Morris D (1985) Integrated model of moulting and feeding of Antarctic krill Euphauisa superba off South Georgia. Mar Ecol Prog Ser 22:207-217

Nicol S (1989) Apparent independence of the spawning and moulting cycles in female Antarctic krill (Euphausia superba Dana) Polar Biol 9:371-375

Nicol S (2000) Understanding krill growth and aging: the contribution of experimental studies. Can J Fish Aquat Sci 57:168-177

Nicol S, Stolp M (1990) A refinement of the moult-staging technique for Antarctic krill (Eupahusia superba). Mar Biol 104:169-173

Paranjape MA (1967) Molting and respiration of euphausiids. J Fish Res Board Can 24:1229-1240

Passano LM (1960) Molting and its control. In: Waterman TH (ed) The physiology of crustacea, Vol 1. Academic Press, New York, p 473-536

Penkoff SJ, Thurberg FP (1982) changes in oxygen consump-

Editorial responsibility: Otto Kinne (Editor), Oldendorf/Luhe, Germany tion of the American lobster, Homarus americanus during the molt cycle. Comp Biochem Physiol 72: 621-622

Peterson BJ, Fry B (1987) Stable isotopes in ecosystem studies. Ann Rev Ecol Syst 18:293-320

Pillar S (1985) Laboratory studies on the larval growth and development of Nyctiphanes capensis (Euphausiacea). J Plankton Res 7:223-240

Priddle J, Watkins J, Morris D, Ricketts C, Buchholz F (1990) Variation of feeding by krill in swarms. J Plankton Res 12:1189-1205

Reaka ML (1976) Lunar and tidal periodicity of molting and reproduction in stomatopod crustacea: a selfish herd hypothesis. Biol Bull (Woods Hole) 150:468-490

Roer DR, Dillaman RM (1993) Molt-related change in integumental structure and function. In: Horst MN, Freeman JA (eds) Crustacean integument morphology and biochemistry. CRC Press, Boca Raton, FL, p 1-37

Sameoto DD (1976) Respiration rates, energy budgets and moulting frequencies of three species of euphausiids found in the Gulf of St. Lawrence. J Fish Res Board Can 33:2568-2576

Schmidt K, Atkinson A, Stübing D, McClelland JW, Montoya JP, Voss M (2003): Trophic relationships among Southern Ocean copepods and krill: Some uses and limitations of a stable isotope approach. Limnol Oceanogr 48:277-289

Skinner DM (1985) Molting and regeneration. In: Bliss DE, Mantel LH (eds) The biology of the crustacea 9; integument, pigments and hormonal processes. Academic Press, New York, p 43-146

Strong KW, Daborn GR (1980) The influence of moulting on the ingestion rate of an isopod crustacean. Oikos 34:159-162

Tarling GA, Cuzin-Roudy J, Buchholz F (1999) Vertical migration behaviour in the northern krill Meganyctiphanes norvegica is influenced by moult and reproductive processes. Mar Ecol Prog Ser 190:253-262

Tarling GA, Cuzin-Roudy J (2003) Synchronization in the molting and spawning activity of northern krill (Meganyctiphanes norvegica) and its effect on recruitment. Limnol Ocenaogr 48:2020-2033

Taylor A, Ross B, McCauley S, Brown JH, Huntingford F (2002) Inter- and intra-individual variation in resting oxygen consumption in post-larvae of the giant freshwater prawn, Macrobrachium rosenbergii (De Man). Comp Biochem Physiol A 132:459-466

Thomasson MA, Johnson ML, Strömberg JO, Gaten E (2003) Swimming capacity and pleopod beat rate as a function of sex, size and moult stage in Northern krill Meganyctiphanes norvegica. Mar Ecol Prog Ser 250:205-213

Tong LJ, Moss GA, Paewai MM, Pickering TD (1997) Effect of brine-shrimp numbers on growth and survival of earlystage phyllosoma larvae of the rock lobster Jasus edwardsii. Mar Freshw Res 48:935-940

Wassenberg TJ, Hill BJ (1984) Moulting behaviour of the tiger prawn Penaeus esculentus (Haswell) Aust J Mar Freshw Res 35:561-571

Submitted: March 23, 2004; Accepted: July 6, 2004

Proofs received from author(s): October 18, 2004 